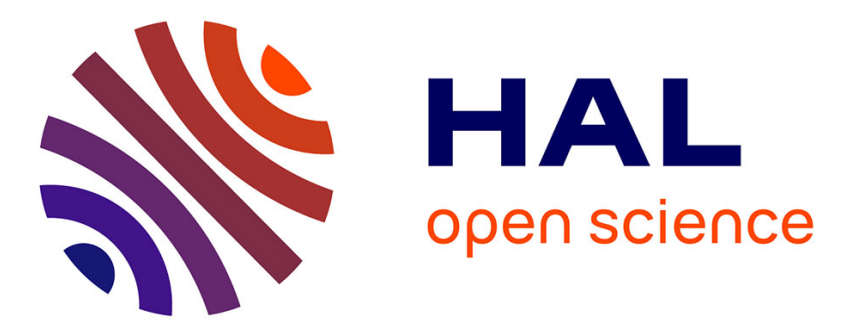

\title{
Direct field oriented control scheme for space vector modulated AC/DC/AC converter fed induction motor
}

Fateh Benchabane, Abdenacer Titaouine, Ouafae Bennis, Khaled Yahia, Djamel Taibi

\section{- To cite this version:}

Fateh Benchabane, Abdenacer Titaouine, Ouafae Bennis, Khaled Yahia, Djamel Taibi. Direct field oriented control scheme for space vector modulated AC/DC/AC converter fed induction motor. Frontiers in Energy, 2013, 6 (2), pp.129-137. 10.1007/s11708-012-0183-0 . hal-00741957

\section{HAL Id: hal-00741957 \\ https://hal.science/hal-00741957}

Submitted on 18 Oct 2012

HAL is a multi-disciplinary open access archive for the deposit and dissemination of scientific research documents, whether they are published or not. The documents may come from teaching and research institutions in France or abroad, or from public or private research centers.
L'archive ouverte pluridisciplinaire HAL, est destinée au dépôt et à la diffusion de documents scientifiques de niveau recherche, publiés ou non, émanant des établissements d'enseignement et de recherche français ou étrangers, des laboratoires publics ou privés. 


\section{F. BENCHABANE, A. TITAOUINE, O. BENNIS, K. YAHIA, D. TAIBI \\ Direct field oriented control scheme for space vector modulated AC/DC/AC converter fed induction motor}

(C) Higher Education Press and Springer-Verlag Berlin Heidelberg 2012

\begin{abstract}
This paper investigates a Luenberger flux observer with speed adaptation for a direct field oriented control of an induction motor. An improved method of speed estimation that operates on the principle of speed adaptive flux and current observer has been proposed. An observer is basically an estimator that uses a plant model and a feedback loop with measured stator voltage and current. Simulation results show that the proposed direct field oriented control with the proposed observer provides good performance dynamic characteristics. The induction motor is fed by an indirect power electronics converter. This indirect converter is controlled by a sliding mode technique that enables minimization of harmonics introduced by the line converter, as well as the control of the power factor and DC-link voltage. The robustness of the overall system is studied using simulation for different operating modes and varied parameters.
\end{abstract}

Keywords induction motor, direct filed oriented control, Luenberger observer, estimation, space vector modulation (SVM), sliding mode control, boost-rectifier

\section{Introduction}

AC induction motor (IM) have been widely used in industrial applications such machine tools, steel mills and paper machines owing to their good performance provided by their solid architecture, low moment of inertia, low ripple of torque and high initiated torque. Some control techniques have been developed to regulate the drives of

Received December 5, 2011; accepted February 14, 2012

F. BENCHABANE ( $($ ) , A. TITAOUINE, K. YAHIA, D. TAIBI

MSE Laboratory, Department of Electrical Engineering, University of Biskra, BP 145 Biskra, Algeria

E-mail: fateh_benchabane@yahoo.fr

O. BENNIS

PRISME Institut, University of Orléans, 21 rue Loigny La Bataille, 28000 Chartres, France these induction motors in high performance applications. One of the most popular techniques is the filed oriented control (direct and indirect) method.

Direct and indirect vector control methods for the speed and torque control of IM have found intensive application in the last two decades. For the indirect control of IM, in addition to the rotor speed, accurate knowledge of the slip frequency (calculated as a function of the IM parameters) is required. On the other hand, direct control of IM necessitates accurate information on the rotor speed, as well as rotor flux as referred to the stator stationary frame [1-3].

Accurate speed information is necessary to realize high performances and high precision speed control of an induction motor. The speed is achieved by using mechanical sensors such as shaft encoder or resolver. However these sensors are usually expensive, bulky and degrade the system reliability, especially in hostile environment. Thus the sensorless control (involving an estimation of speed) becomes a major subject and an attractive task to industrial applications. Since 1980's, speed sensorless control methods of induction motor using the estimated speed instead of the measured speed have been studied [1,2]. The speed has been estimated from the instantaneous values of stator voltages and currents using the induction motor model.

This paper presents the development of flux Luenberger observer with speed adaptation for the direct filed oriented control of an IM. The speed estimation algorithm utilizes the rotor flux and the stator current obtained by means of Luenberger observer.

A three-phase converter is used in this work. The power converter can only flow from $\mathrm{AC}$ to $\mathrm{DC}$, and the line current is not continuous. Because this type of AC-DC conversion does not control line current harmonics, the displacement power factor is poor and the DC side voltage is not constant $[4,5]$. One remedy is a reversible converter to replace the diode-bridge rectifier and to allow a reversible power line flow which allows the energy recovered from motor-load inertia to be fed back to the 
utility supply $[4,6]$. The DC-link voltage can be regulated by the sliding mode controller.

\section{Induction motor model}

For the purpose of using Luenberger observer for the estimation of the rotor flux of an induction machine, it is possible to use various machine models. For example, it is possible to use the equations expressed in the rotor fluxoriented reference frame, or in stator flux-oriented reference frame. In order to avoid extra calculations and non-linear transformations, stationary reference frame is preferred. The main advantages of using the model in stationary reference frame are reduced computation time, less sampling time, higher accuracy, more stable behavior [3]. Thus, the stationary reference frame has been chosen in the study. So, the fourth order dynamic model for induction machine developed in stationary reference frame $(\alpha, \beta)$ is

$$
\begin{aligned}
& \dot{x}=A x+B u, \\
& y=C x,
\end{aligned}
$$

where

$$
\boldsymbol{x}=\left[\begin{array}{llll}
i_{\mathrm{s} \alpha} & i_{\mathrm{s} \beta} & \psi_{\mathrm{r} \alpha} & \psi_{\mathrm{r} \beta}
\end{array}\right]^{\mathrm{T}}, \quad \boldsymbol{u}=\left[\begin{array}{ll}
u_{\mathrm{s} \alpha} & u_{\mathrm{s} \beta}
\end{array}\right]^{\mathrm{T}}, \quad \boldsymbol{y}=\left[\begin{array}{ll}
i_{\mathrm{s} \alpha} & i_{\mathrm{s} \beta}
\end{array}\right]^{\mathrm{T}},
$$

with $\boldsymbol{x}, \boldsymbol{u}, \boldsymbol{y}$ are the state vector, the input vector and the output vector respectively.

$$
\begin{gathered}
\boldsymbol{A}=\left[\begin{array}{cccc}
\gamma & 0 & \frac{K_{1}}{T_{\mathrm{r}}} & p K_{\mathrm{l}} \Omega \\
0 & \gamma & p K_{\mathrm{l}} \Omega & \frac{K_{1}}{T_{\mathrm{r}}} \\
\frac{L_{\mathrm{m}}}{T_{\mathrm{r}}} & 0 & \frac{1}{T_{\mathrm{r}}} & p \Omega \\
0 & \frac{L_{\mathrm{m}}}{T_{\mathrm{r}}} & p \Omega & \frac{1}{T_{\mathrm{r}}}
\end{array}\right], \\
\boldsymbol{B}=\frac{1}{\sigma L_{\mathrm{s}}}\left[\begin{array}{ll}
1 & 0 \\
0 & 1 \\
0 & 0 \\
0 & 0
\end{array}\right], \quad \boldsymbol{C}=\left[\begin{array}{ll}
1 & 0 \\
0 & 1 \\
0 & 0 \\
0 & 0
\end{array}\right]^{\mathrm{T}}, \\
\sigma=1-\frac{L_{\mathrm{m}}^{2}}{L_{\mathrm{s}} L_{\mathrm{r}}}, \gamma=\frac{R_{\mathrm{s}}}{\sigma L_{\mathrm{s}}}+\frac{R_{\mathrm{r}} L_{\mathrm{m}}^{2}}{\sigma L_{\mathrm{s}} L_{\mathrm{r}}^{2}}, K_{1}=\frac{L_{\mathrm{m}}}{\sigma L_{\mathrm{s}} L_{\mathrm{r}}}, T_{\mathrm{r}}=\frac{L_{\mathrm{r}}}{R_{\mathrm{r}}}
\end{gathered}
$$

\section{Modeling and control of the boost rectifier}

3.1 Modeling of the boost rectifier

The proposed system configuration is shown in Fig. 1.

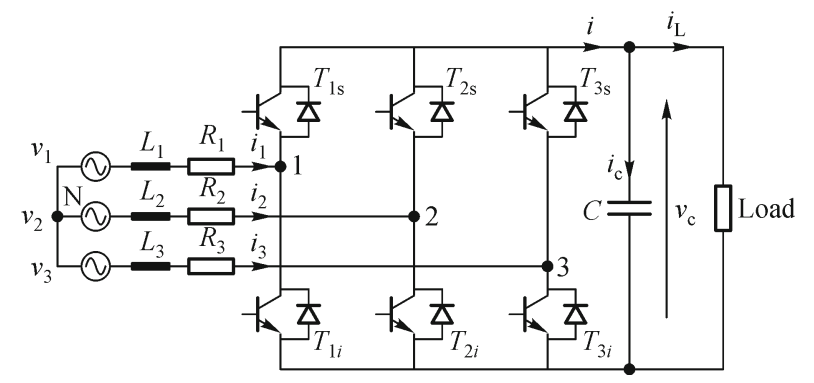

Fig. 1 Rectifier configuration

This circuit will be analyzed under the following assumptions [7,8]:

1) The input AC voltage is a balanced three-phase supply;

2) The power switches are ideal;

3) All circuit elements are linear and time invariant.

The source voltages are assumed to be balanced and are given by

$$
\begin{aligned}
& v_{1}=v_{\mathrm{m}} \cos (\omega t), \\
& v_{2}=v_{\mathrm{m}} \cos (\omega t-2 \pi / 3), \\
& v_{3}=v_{\mathrm{m}} \cos (\omega t+2 \pi / 3),
\end{aligned}
$$

where $v_{\mathrm{m}}$ and $\omega$ are respectively the amplitude of the phase voltage and angular pulsation of the power source.

Referring to Fig. 1, using Kirchhoff's voltage law on the AC side, it yields

$$
L \frac{\mathrm{d}}{\mathrm{d} t} i_{k}+R i_{k}=v_{k}-\left(v_{k 0}+v_{0 n}\right), \quad(k=1,2,3),
$$

where $k$ indicates the $k$ phase.

The switching functions $S_{k}$ defined for the $k$ of the converter are given by

$$
\begin{array}{ll}
S_{k}=1, & \text { if } T_{k \mathrm{~s}} \text { is on and } T_{k i} \text { is off, } \\
S_{k}=0, & \text { if } T_{k \mathrm{~s}} \text { is off and } T_{k i} \text { is on. }
\end{array}
$$

By considering the switching functions $S_{k}$, one can obtain

$$
\begin{array}{cc}
v_{k 0}=v_{\mathrm{c}}, & \text { if } S_{k}=1, \\
v_{k 0}=0, & \text { if } S_{k}=0, \\
v_{0 N}=-\frac{v_{\mathrm{c}}}{3} \sum_{k=1}^{3} S_{k}, & (k=1,2,3) .
\end{array}
$$

Applying the Kirchhoff's current law on the DC side and using Eq. (5), one can write

$$
\begin{gathered}
L \frac{\mathrm{d}}{\mathrm{d} t} i_{k}=v_{k}-R i_{k}-S_{k} v_{\mathrm{c}}+\frac{v_{\mathrm{c}}}{3} \sum_{k=1}^{3} S_{k},(k=1,2,3), \\
C \frac{\mathrm{d}}{\mathrm{d} t} v_{\mathrm{c}}=\sum_{k=1}^{3} S_{k} i_{k}-i_{L}, \quad(k=1,2,3) .
\end{gathered}
$$


The following state-space model of the rectifier, in the three-phase reference frame, can be obtained by

$$
\begin{aligned}
\frac{\mathrm{d}}{\mathrm{d} t}\left[\begin{array}{l}
i_{1} \\
i_{2} \\
i_{3} \\
v_{\mathrm{c}}
\end{array}\right]= & {\left[\begin{array}{ccccc}
-\frac{R}{L} & 0 & 0 & 0 & 0 \\
0 & -\frac{R}{L} & 0 & 0 & 0 \\
0 & 0 & -\frac{R}{L} & 0 & 0 \\
0 & 0 & 0 & 0 & 0
\end{array}\right]\left[\begin{array}{c}
i_{1} \\
i_{2} \\
i_{3} \\
v_{\mathrm{c}}
\end{array}\right] } \\
+ & {\left[\begin{array}{cccc}
\frac{-2 v_{\mathrm{c}}}{3 L} & \frac{v_{\mathrm{c}}}{3 L} & \frac{v_{\mathrm{c}}}{3 L} \\
\frac{v_{\mathrm{c}}}{3 L} & \frac{-2 v_{\mathrm{c}}}{3 L} & \frac{v_{\mathrm{c}}}{3 L} \\
\frac{2 v_{\mathrm{c}}}{3 L} & \frac{v_{\mathrm{c}}}{3 L} & \frac{-2 v_{\mathrm{c}}}{3 L} \\
\frac{i_{1}}{C} & \frac{i_{2}}{C} & \frac{i_{3}}{C}
\end{array}\right]\left[\begin{array}{l}
S_{1} \\
S_{2} \\
S_{3}
\end{array}\right] } \\
+ & {\left[\begin{array}{cccc}
\frac{1}{L} & 0 & 0 & 0 \\
0 & \frac{1}{L} & 0 & 0 \\
0 & 0 & \frac{1}{L} & 0 \\
0 & 0 & 0 & -\frac{1}{C}
\end{array}\right]\left[\begin{array}{l}
v_{1} \\
v_{2} \\
v_{3} \\
i_{\mathrm{L}}
\end{array}\right] . }
\end{aligned}
$$

According to Eq. (6), one can state that the main problem in the design of a control law of the boost rectifier is the occurrence of control input function in both AC current $\left(i_{k}\right)$ and DC voltage $\left(v_{\mathrm{c}}\right)$ control systems of the converter. Both input functions depend on the same duty ration $S_{k}$ by different dynamic behavior of $\mathrm{AC}$ input and DC output of the boost rectifier. Input main voltages and currents should be sinusoidal shaped without phase delay between voltage and current, and output DC voltage should have a constant value by change of voltage dependent current and parameters of the converter $[7,9]$.

\subsection{Sliding mode control of the rectifier}

The block diagram of regulation is illustrated in Fig. 2 . According to Fig. 2, the DC bus voltage error $\left(v_{\text {cref }}-v_{\mathrm{c}}\right)$ is used to synthesize a line current reference $I_{\text {ref }}$ from a sliding mode controller (SMC). The currents references $i_{1 \text { ref }}, i_{2 \text { ref }}$ are generated from a sinusoidal model obtained through the multiplication of the current reference $I_{\text {ref }}$ by the input voltage, in order to ensure a working with a unity power factor $[7,10]$, the instantaneous and input currents are compared and the error signals are generated from which the comparators with hysteresis produce switch impulses.

To control the output DC voltage of the rectifier, the

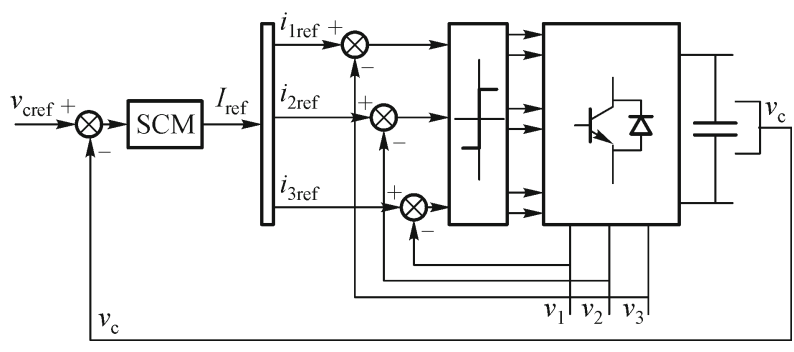

Fig. 2 DC voltage control model with sliding mode controller

SMC can be used $[7,10]$. Through the sliding surface, the current $I_{\text {ref }}$ is given by

$$
I_{\text {ref }}=K_{\mathrm{c}} \operatorname{sgn}\left(v_{\text {cref }}-v_{\mathrm{c}}\right) .
$$

\section{Space vector modulation (SVM)}

In space vector modulation techniques, the reference voltages are given by space voltage vector and the output voltages of the inverter are considered as space vectors. There are eight possible output voltage vectors, six active vectors $\boldsymbol{u}_{1}-\boldsymbol{u}_{6}$, and two zero vectors $\boldsymbol{u}_{0}, \boldsymbol{u}_{7}$ (Fig. 3). The reference voltage vector is realized by the sequential switching of active and zero vectors. Figure 1 shows reference voltage vector $\boldsymbol{u}_{\text {ref }}$ and eight voltage vectors, which correspond to the possible states of inverter. The six active vectors divide a plane for the six sectors $1-6$. In each sector, the reference voltage vector $\boldsymbol{u}_{\text {ref }}$ is obtained by switching on two adjacent vectors for an appropriate duration. As seen in Fig. 1 the reference vector $\boldsymbol{u}_{\text {ref }}$ can be implemented by the switching vectors of $\boldsymbol{u}_{1}, \boldsymbol{u}_{2}$ and zero vectors $\boldsymbol{u}_{0}, \boldsymbol{u}_{7}[11,12]$.

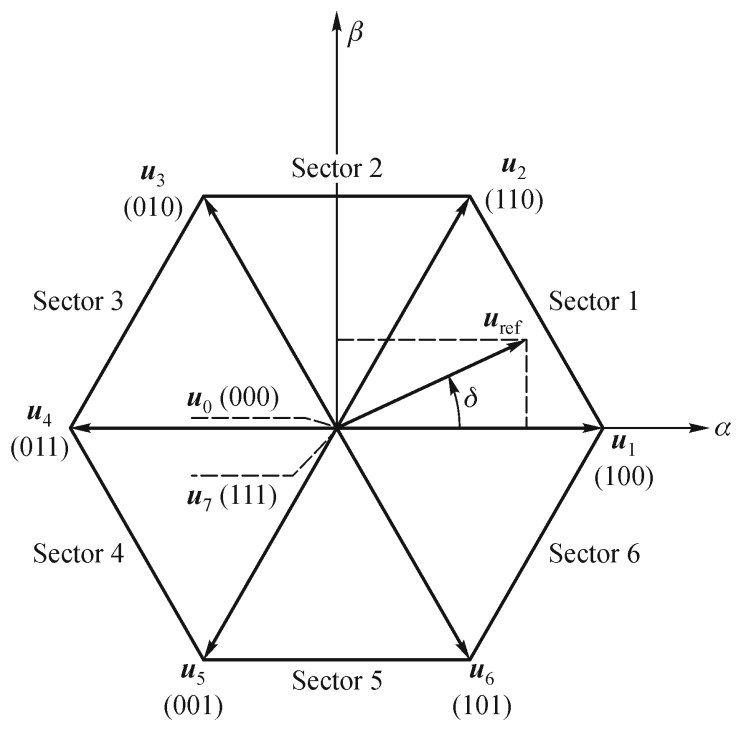

Fig. 3 Principle of space vector modulation 
The six active tension vectors can be formulated by

$$
\overline{\boldsymbol{u}}_{i}=\sqrt{\frac{2}{3}} \boldsymbol{u}_{\mathrm{dc}} \mathrm{e}^{\mathrm{j}(i-1) \frac{\pi}{3}},(i=1,2,3,4,5,6),
$$

where $\boldsymbol{u}_{\mathrm{dc}}$ is a dc voltage.

Figure 4 displays the case when the reference vector is in sector 1 . The times $T_{1}$ and $T_{2}$ are obtained by simple trigonometrical relationships and can be expressed as

$$
\left\{\begin{array}{l}
T=T_{1}+T_{2}+T_{0}, \\
\overline{\boldsymbol{u}}_{\mathrm{ref}}=\frac{T_{1}}{T} \overline{\boldsymbol{u}}_{1}+\frac{T_{2}}{T} \overline{\boldsymbol{u}}_{2},
\end{array}\right.
$$

and

$$
\left\{\begin{array}{l}
u_{\mathrm{s} \beta \mathrm{ref}}=\frac{T_{2}}{T}\left|\overline{\boldsymbol{u}}_{2}\right| \cos 30^{\circ}, \\
u_{\mathrm{s} \alpha \mathrm{ref}}=\frac{T_{1}}{T}\left|\overline{\boldsymbol{u}}_{1}\right|+x, \\
x=\frac{u_{\mathrm{s} \beta \mathrm{ref}}}{\tan 60^{\circ}} .
\end{array}\right.
$$

Finally, according to Eq. (2), the application periods of every vector is given by

$$
\left\{\begin{array}{l}
T_{1}=\frac{T}{2 u_{\mathrm{dc}}}\left(\sqrt{6} u_{\mathrm{saref}}-\sqrt{2} u_{\mathrm{s} \beta \mathrm{ref}}\right), \\
T_{2}=\sqrt{2} \frac{T}{u_{\mathrm{dc}}} u_{\mathrm{s} \beta \mathrm{ref}} .
\end{array}\right.
$$

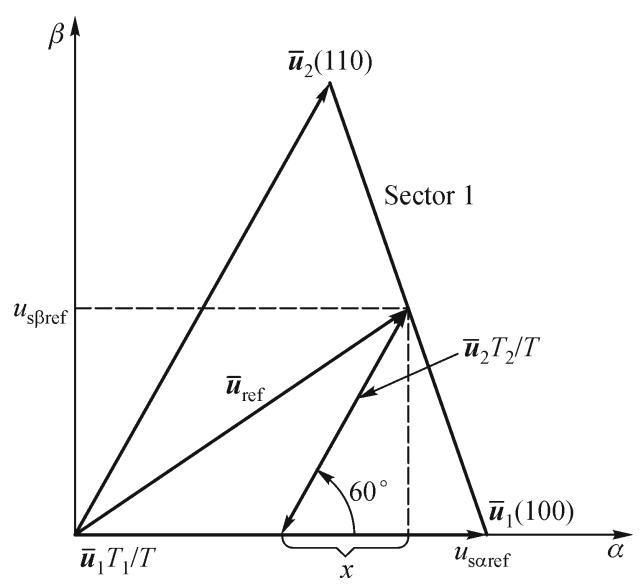

Fig. 4 Projection of the reference vector (sector 1)

\section{Flux Luenberger observer and speed adaptation}

Accurate and robust estimation of motor variables which are not measured is crucial for high performance sensorless drives. A multitude observers have been proposed, but only a few are able to sustain persistent and accurate wide speed range sensorless operation. At very low speed, their performances are poor. One of the raisons is high sensitivity of the observers to unmodeled nonlinearities, disturbance and model parameters detuning $[12,13]$.

The Luenberger observer, which estimates states of the system (stator current and rotor flux), is defined by

$$
\dot{\hat{\boldsymbol{x}}}=\hat{\boldsymbol{A}} \hat{\boldsymbol{x}}+\boldsymbol{B} \boldsymbol{u}+\boldsymbol{G C}(\boldsymbol{x}-\hat{\boldsymbol{x}}),
$$

where the symbol ( ${ }^{\wedge}$ ) represents the estimated value and $\boldsymbol{G}$ is the observer gain matrix. It should be noted that, since there are no speed sensors, the speed signal $\omega_{\mathrm{r}}$ is considered as an unknown parameter in the matrix $\boldsymbol{A}$, and therefore the observer equation has $\hat{\boldsymbol{A}}$ instead of $\boldsymbol{A}$.

If the speed signal $\omega_{\mathrm{r}}$ in parameter matrix $\boldsymbol{A}$ were known, the fluxes and currents could be solved from the observer presented in Eq. (13). However, the speed signal is unknown and therefore the estimation of these states requires the precious estimation of this signal. Thus, an adaptive scheme, derived from Lyapunov's stability theorem, will be proposed for estimating the rotor speed $\hat{\omega}_{\mathrm{r}}$ in the matrix $\hat{\boldsymbol{A}}$.

The estimation error of the system states (stator currents and rotor fluxes) may be obtained subtracting Eqs. (1) and (13) as

$$
\begin{aligned}
\dot{\boldsymbol{x}}-\dot{\hat{\boldsymbol{x}}} & =\boldsymbol{A} \boldsymbol{x}-\hat{\boldsymbol{A}} \hat{\boldsymbol{x}}-\boldsymbol{G C}(\boldsymbol{x}-\hat{\boldsymbol{x}}) \\
& =\boldsymbol{A} \boldsymbol{x}-\boldsymbol{A} \hat{\boldsymbol{x}}+(\boldsymbol{A}-\hat{\boldsymbol{A}}) \hat{\boldsymbol{x}}-\boldsymbol{G} \boldsymbol{C}(\boldsymbol{x}-\hat{\boldsymbol{x}}) \\
& =(\boldsymbol{A}-\boldsymbol{G} \boldsymbol{C})(\boldsymbol{x}-\hat{\boldsymbol{x}})+\left(\omega_{\mathrm{r}}-\hat{\omega}_{\mathrm{r}}\right) \boldsymbol{M} \hat{\boldsymbol{x}},
\end{aligned}
$$

where $\boldsymbol{M}$ is a constant matrix defined as

$$
\boldsymbol{M}=\left[\begin{array}{cccc}
0 & 0 & 0 & K_{1} \\
0 & 0 & -K_{1} & 0 \\
0 & 0 & 0 & -1 \\
0 & 0 & 1 & 0
\end{array}\right] .
$$

Then the following estimation error dynamic is obtained:

$$
\dot{\tilde{\boldsymbol{x}}}=(\boldsymbol{A}-\boldsymbol{G C}) \tilde{\boldsymbol{x}}+\hat{\omega}_{\mathrm{r}} \boldsymbol{M} \hat{\boldsymbol{x}},
$$

where $\tilde{\boldsymbol{x}}=\boldsymbol{x}-\hat{\boldsymbol{x}}$ is the state estimation error and $\tilde{\omega}_{\mathrm{r}}=$ $\omega_{\mathrm{r}}-\hat{\omega}_{\mathrm{r}}$ is the rotor speed error.

Let us define the following Lyapunov function candidate:

$$
V=\frac{1}{2} \tilde{\boldsymbol{x}}^{\mathrm{T}} \tilde{\boldsymbol{x}}+\frac{1}{2} \frac{\tilde{\omega}_{\mathrm{r}}^{2}}{\lambda},
$$

where $\lambda$ is a positive constant.

On the basis of the fact that the velocity of outer control loop is much slower than the estimated inner loop, hence the assumption of approaching a constant is reasonable on 
deriving the following equations $[14,15]$. Then, the time derivative of $V$ becomes

$$
\begin{aligned}
\dot{V} & =\tilde{\boldsymbol{x}}^{\mathrm{T}} \tilde{\boldsymbol{x}}+\frac{\tilde{\omega}_{\mathrm{r}} \dot{\tilde{\omega}}}{\lambda} \\
& =\tilde{\boldsymbol{x}}^{\mathrm{T}}(\boldsymbol{A}-\boldsymbol{G C}) \tilde{\boldsymbol{x}}+\tilde{\boldsymbol{x}}^{\mathrm{T}} \tilde{\omega}_{\mathrm{r}} \boldsymbol{M} \tilde{\boldsymbol{x}}-\frac{\tilde{\omega}_{\mathrm{r}} \dot{\tilde{\omega}}}{\lambda} \\
& =\tilde{\boldsymbol{x}}^{\mathrm{T}}(\boldsymbol{A}-\boldsymbol{G C}) \tilde{\boldsymbol{x}}+\frac{\tilde{i}_{\mathrm{ds}} \hat{\psi}_{\mathrm{qr}}-\tilde{i}_{\mathrm{qs}} \hat{\psi}_{\mathrm{dr}}}{c} \tilde{\omega}_{\mathrm{r}}-\frac{\tilde{\omega}_{\mathrm{r}} \dot{\tilde{\omega}}}{\lambda},
\end{aligned}
$$

where $\hat{i}_{\mathrm{ds}}=i_{\mathrm{ds}}-\hat{i}_{\mathrm{ds}}$ and $\tilde{i}_{\mathrm{qs}}=i_{\mathrm{qs}}-\hat{i}_{\mathrm{qs}}$.

The adaptation algorithm for speed estimation is derived equalizing the second term with the third term, which is

$$
\dot{\hat{\omega}}=\frac{\lambda}{c}\left(\tilde{i}_{\mathrm{ds}} \hat{\psi}_{\mathrm{qr}}-\tilde{i}_{\mathrm{qs}} \hat{\psi}_{\mathrm{dr}}\right),
$$

then the time derivative of $V$ is reduced to

$$
\dot{V}=\tilde{\boldsymbol{x}}^{\mathrm{T}}(\boldsymbol{A}-\boldsymbol{G} \boldsymbol{C}) \tilde{\boldsymbol{x}} .
$$

If the observer gain $G$ is chosen such that the time derivative of $V$ is negative semidefinite, then $V$ is a positive definite and decreasing function, which implies that $V$ is bounded. Therefore from Eq. (15), it is found that $\tilde{x}$ and $\tilde{\omega}_{\mathrm{r}}$ are bounded. This implies that the estimated states $\tilde{x}$ and the estimated rotor speed are bounded, because the real states $\boldsymbol{x}$ and the rotor electrical speed $\omega_{\mathrm{r}}$ are bounded.

The second derivative of $V$ is

$$
\begin{aligned}
\ddot{V} & =2 \tilde{\boldsymbol{x}}^{\mathrm{T}}(\boldsymbol{A}-\boldsymbol{G C}) \dot{\tilde{\boldsymbol{x}}} \\
& =2 \tilde{\boldsymbol{x}}^{\mathrm{T}}(\boldsymbol{A}-\boldsymbol{G C})^{2} \tilde{\boldsymbol{x}}+2 \tilde{\boldsymbol{x}}^{\mathrm{T}}(\boldsymbol{A}-\boldsymbol{G C}) \tilde{\omega}_{\mathrm{r}} \boldsymbol{M} \hat{\boldsymbol{x}},
\end{aligned}
$$

which is bounded quantity because $\tilde{\boldsymbol{x}}, \tilde{\omega}_{\mathrm{r}}$ and $\tilde{\boldsymbol{x}}$ are pounded.

Under these conditions, since $\ddot{V}$ is bounded, then $\dot{V}$ is uniformly continuous function, so Barbalat's lemma makes it possible to conclude that [14]

$$
\dot{V} \rightarrow 0 \quad \text { as } \quad t \rightarrow \infty .
$$

Therefore the estimated states $\hat{i}_{\mathrm{s} \alpha}, \hat{i}_{\mathrm{s} \beta}, \hat{\psi}_{\mathrm{r} \alpha}, \hat{\psi}_{\mathrm{r} \beta}$ converges to the real states $i_{\mathrm{s} \alpha}, i_{\mathrm{s} \beta}, \psi_{\mathrm{r} \alpha}, \psi_{\mathrm{r} \beta}$ as $t$ tends to infinity. In consequence, the rotor flux may be obtained from the state Luenberger observer given by Eq. (13) and the rotor speed adaptation algorithm proposed in Eq. (16).

Taking the derivative of Eq. (14) it is obtained that

$$
\begin{aligned}
\ddot{\tilde{\boldsymbol{x}}}= & (\boldsymbol{A}-\boldsymbol{G} \boldsymbol{C}) \dot{\tilde{\boldsymbol{x}}}+\dot{\tilde{\omega}}_{\mathrm{r}} \boldsymbol{M} \hat{\boldsymbol{x}}+\tilde{\omega}_{\mathrm{r}} \boldsymbol{M} \dot{\hat{\boldsymbol{x}}} \\
= & (\boldsymbol{A}-\boldsymbol{G C})\left[(\boldsymbol{A}-\boldsymbol{G C}) \tilde{\boldsymbol{x}}+\tilde{\omega}_{\mathrm{r}} \boldsymbol{M} \hat{\boldsymbol{x}}\right]-\dot{\tilde{\omega}}_{\mathrm{r}} \boldsymbol{M} \hat{\boldsymbol{x}} \\
& +\tilde{\omega}_{\mathrm{r}} \boldsymbol{M}[\hat{\boldsymbol{A}} \tilde{\boldsymbol{x}}+\boldsymbol{B} \boldsymbol{u}-\boldsymbol{G C}(\boldsymbol{x}-\hat{\boldsymbol{x}})] .
\end{aligned}
$$

From Eq. (20), it may be concluded that $\ddot{\tilde{\boldsymbol{x}}}$ is bounded because all the quantities in this equation are bounded. Then, as $\tilde{\boldsymbol{x}}$ is a convergent function (converge to zero) and $\ddot{\tilde{\boldsymbol{x}}}$ is bounded, from Barbalat's lemma. it can be concluded that

$$
\dot{\tilde{\boldsymbol{x}}} \rightarrow \mathbf{0} \quad \text { as } \quad t \rightarrow \infty .
$$

Therefore when $t \rightarrow \infty$, from Eqs. (14), (19) and (21) it is concluded that

$$
\begin{aligned}
\dot{\tilde{\boldsymbol{x}}} & =(\boldsymbol{A}-\boldsymbol{G C}) \tilde{\boldsymbol{x}}+\tilde{\omega}_{\mathrm{r}} \boldsymbol{M} \hat{\boldsymbol{x}}, \\
\mathbf{0} & =(\boldsymbol{A}-\boldsymbol{G} \boldsymbol{C}) \mathbf{0}+\tilde{\omega}_{\mathrm{r}} \boldsymbol{M} \hat{\boldsymbol{x}}, \\
\mathbf{0} & =\tilde{\omega}_{\mathrm{r}} \boldsymbol{M} \hat{\boldsymbol{x}} .
\end{aligned}
$$

Then, as $\boldsymbol{M}$ and $\hat{\boldsymbol{x}}$ are not zero, Eq. (22) implies that.

$$
\tilde{\omega}_{\mathrm{r}} \rightarrow 0 \quad \text { as } \quad t \rightarrow \infty .
$$

Therefore the estimated rotor speed $\hat{\omega}_{\mathrm{r}}$ converge to the real rotor speed $\omega_{\mathrm{r}}$ as $t$ tends to infinity.

\section{Sensorless drive}

The Luenberger observer with speed adaptation is applied to an induction motor direct field oriented controlled as demonstrated in Fig. 5.

\section{Simulation results}

\subsection{Simulation results of SMC rectifier}

The simulation conditions are given in the appendix. In order to demonstrate the feasibility of the proposed control method, the system depicted in Fig. 6 has been simulated. It is indicated clearly in Fig. 6 that the output voltage of the rectifier is well controlled to $540 \mathrm{~V}$. Therefore, the output DC voltage response is completely robust with the unity power factor at the $\mathrm{AC}$ side of the boost rectifier.

\subsection{Simulation results of sensorless control for IM}

The induction motor used for the simulation studies has been presented in the appendix.

Figure 7 shows the speed step response of $100 \mathrm{rad} / \mathrm{s}$ with $0.4 \mathrm{~s}$ a time rating load of $25 \mathrm{~N} \cdot \mathrm{m}$. The good estimation of the motor speed with a few rad/s errors can be noticed in transient state and when load applied. For the flux estimation, the results demonstrate that the real and estimated flux modules are the same, apart from a negligible error. As a consequence, the simulation results demonstrate that the proposed Luenberger observer avec 


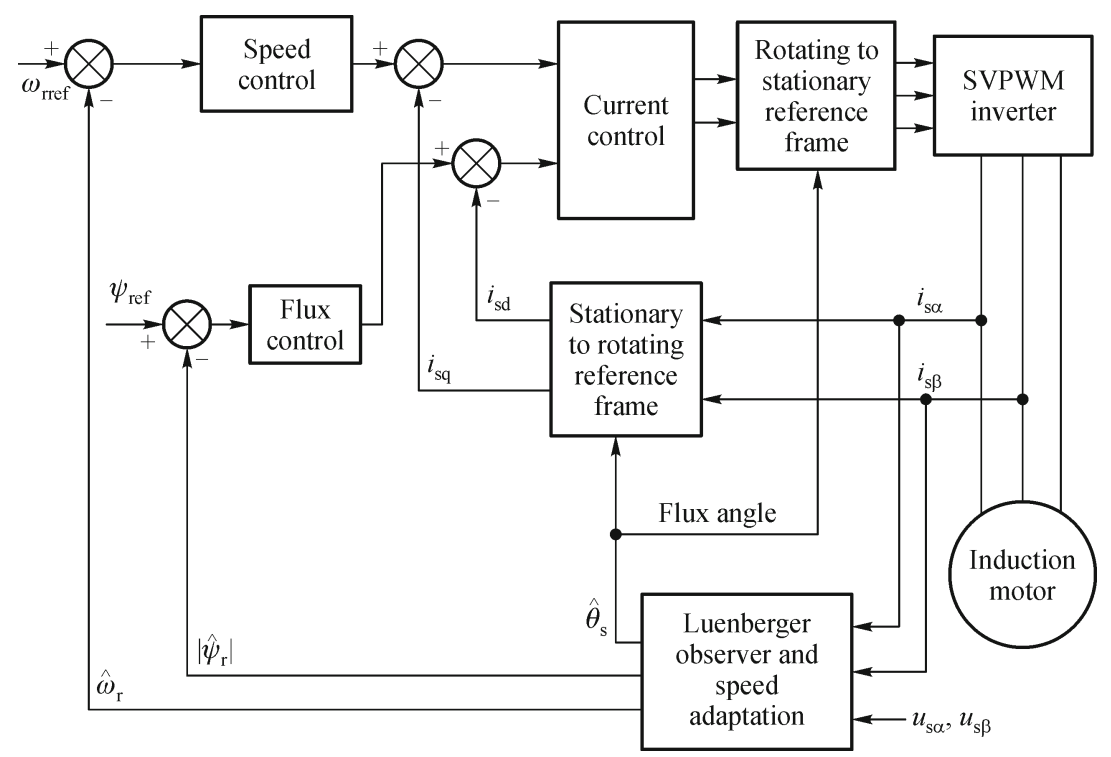

Fig. 5 Speed control of an induction machine using direct field oriented control method and a Luenberger flux observer with speed adaptation

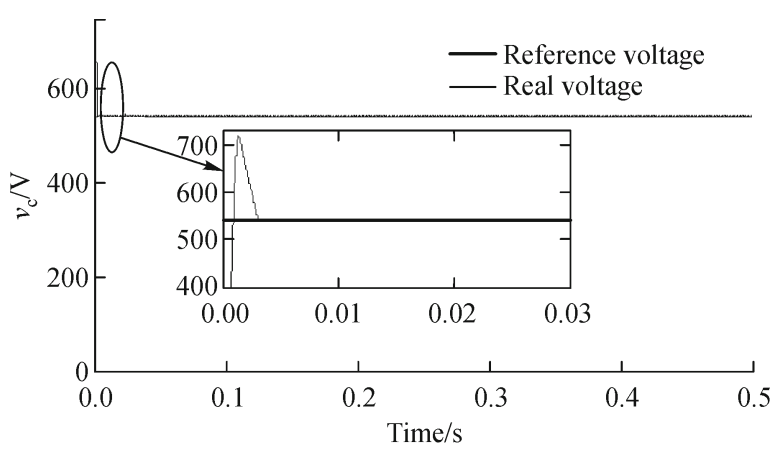

Fig. 6 Simulation results of the rectifier output voltage

speed adaptation can guarantee acceptable performances of the sensorless direct field oriented control in the step response of $100 \mathrm{rad} / \mathrm{s}$ with an applied load of $25 \mathrm{~N} \cdot \mathrm{m}$ without causing instability.

In Fig. 8, good performances of flux and speed estimation obtained by the Luenberger flux observer and speed estimation can be noticed. Therefore, in the low speed regions, these performances are acceptable. All the sensorless direct field oriented control system characteristics demonstrate good performances of regulation and a high stability of the global system.

\section{Conclusions}

The detailed design procedure for the Luenberger flux observer with speed adaptation has been presented and used for the speed sensorless direct vector control of an induction motor. The knowledge of the rotor space vector position is essential to implement the direct field-oriented control strategy to induction motor drives.

For the rectifier, performances of the SMC are evaluated through the simulation of this model. The obtained results show the efficiency and the precision of this control.

The Luenberger flux observer with speed adaptation has been successfully applied to induction motor sensorless drive system. It can be concluded from the simulation results that the estimation of rotor flux and rotor speed has been done satisfactory. The bad performances of estimation in low speed can be caused by the bad tuning of the adaptive mechanism parameters and poles choice.

\section{Appendix}

Parameters of the IM:

Type: tree-phase, $4 \mathrm{~kW}$. 220/380 V, squirrel-cage induction motor.

$R_{\mathrm{S}}=1.2 \Omega ; R_{\mathrm{r}}=1.8 \Omega ; L_{\mathrm{S}}=0.1554 \mathrm{H} ; L_{\mathrm{r}}=0.1568 \mathrm{H} ;$

$L_{\mathrm{m}}=0.15 \mathrm{H} ; J=0.07 \mathrm{~kg} \cdot \mathrm{m}^{2} ; f_{\mathrm{r}}=0.001 \mathrm{~N} \cdot \mathrm{m} \cdot \mathrm{s} / \mathrm{rad} ;$

$p=2 ; T_{1}=25 \mathrm{~N} \cdot \mathrm{m} ; \Omega=150 \mathrm{rad} / \mathrm{s}$.

Parameters of the pulse-width modulation (PWM) converter:

Supply's voltage and frequency: $220 \mathrm{~V}(\mathrm{rms}), 50 \mathrm{~Hz}$;

Line's inductor and resistance $0.002 \mathrm{H}, 0.08 \Omega$;

Output capacitors $0.0025 \mathrm{~F}$;

PWM carrier frequency $1 \mathrm{kHz}$. 
Real (solid line) and estimated (dashed line) speed

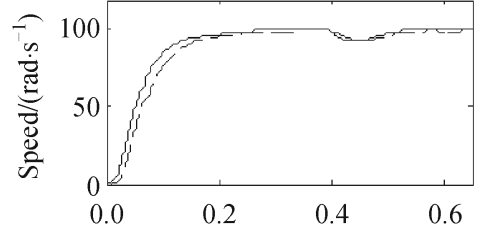

Real $a$-axis flux

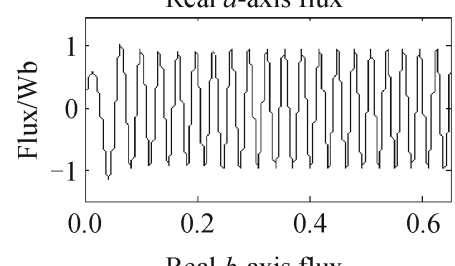

Real $b$-axis flux

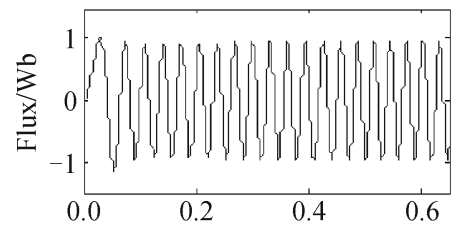

Real (solid line) and estimated (dashed line) flux modulus
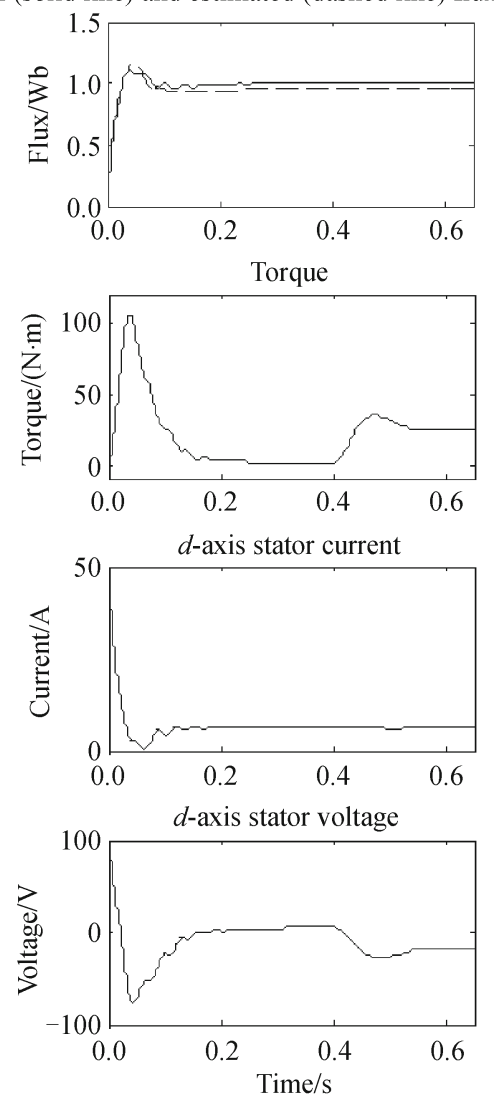
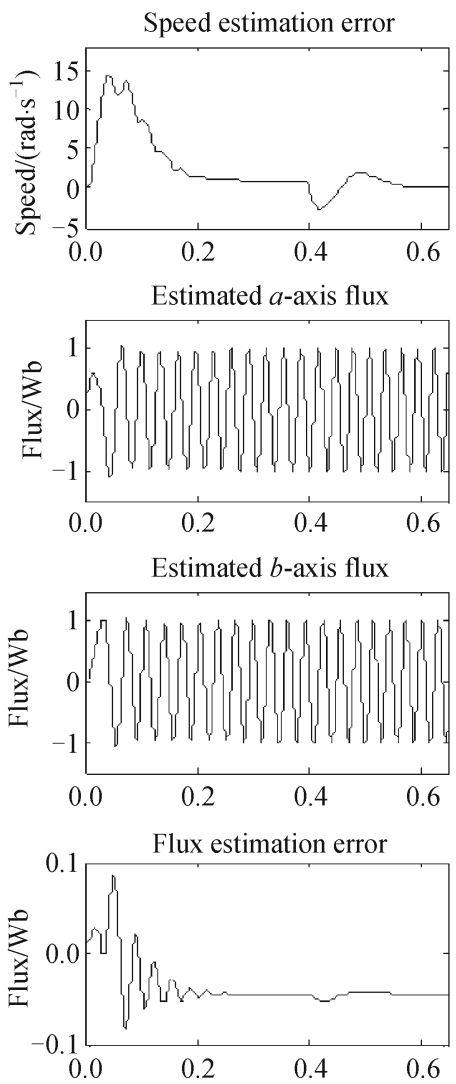

$d$ (solid line)- $q$ (dashed line) rotor fluxes

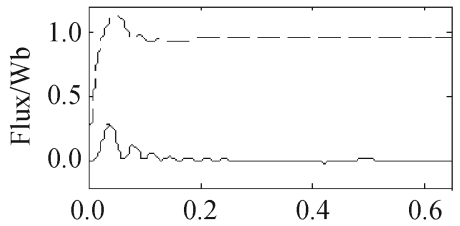

$q$-axis stator current
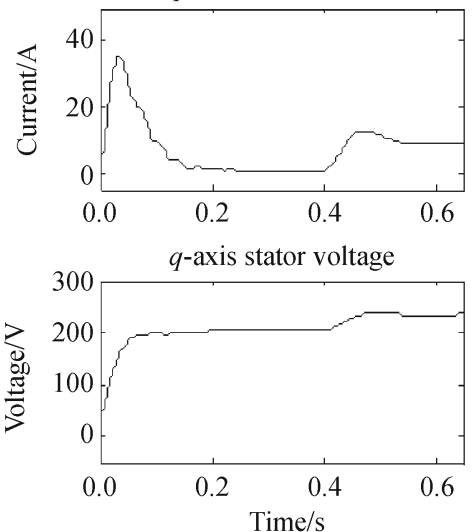

Fig. 7 Simulation results: dynamic behavior of the sensorless controller with maximum speed equal to $100 \mathrm{rad} / \mathrm{s}$ and applied load torque equal to $25 \mathrm{~N} \cdot \mathrm{m}$ 
Real (solid line) and estimated (dashed line) speed
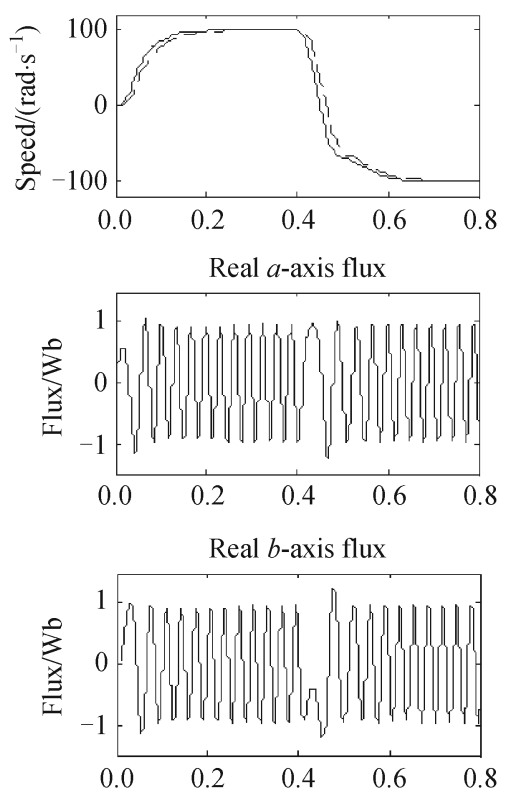

Real (solid line) and estimated (dashed line) flux modulus
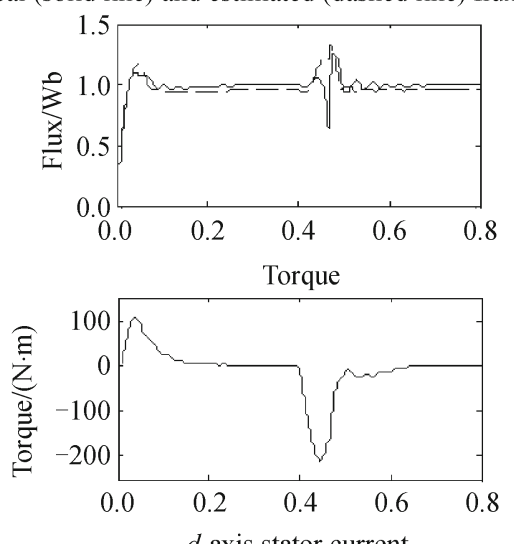

$d$-axis stator current
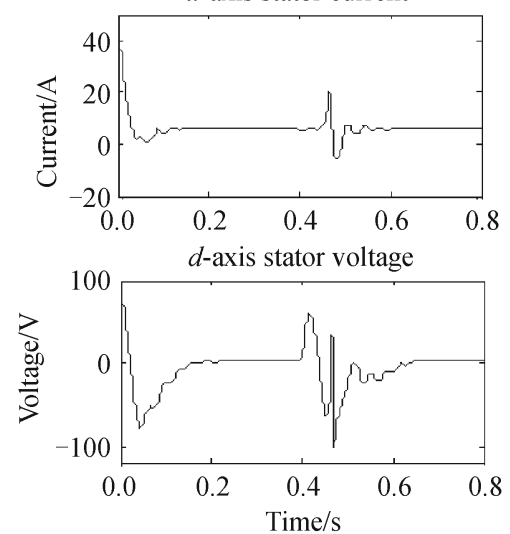
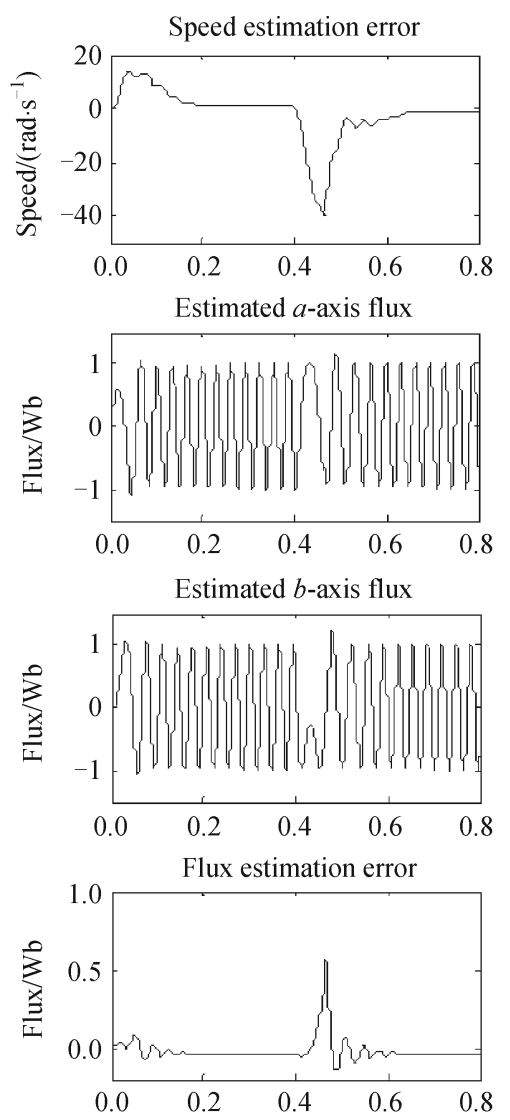

$d$ (solid line)- $q$ (dashed ine) rotor fluxes

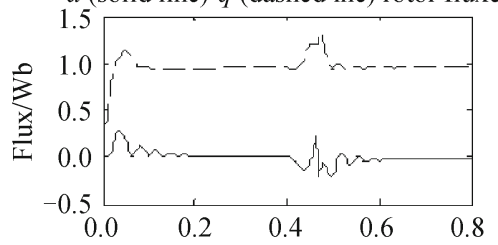

$q$-axis stator current
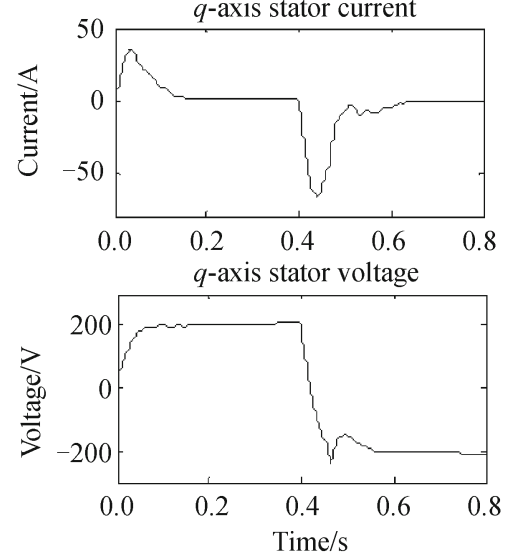

Fig. 8 Simulation results: dynamic behavior of the sensorless controller with speed reversal from $100 \mathrm{rad} / \mathrm{s}$ to $-100 \mathrm{rad} / \mathrm{s}$ at $0.4 \mathrm{~s} \mathrm{for}$ unloaded induction motor 


\section{References}

1. Barut M, Bogosyan O S, Gokasan M. An extended Kalman filter based sensorless direct vector control of induction motors. In: IECON'03. 29th Annual Conference of the IEEE Industrial Electronics Society. Roanoke, USA, 2003, 318-322

2. Sturtzer G, Smigiel E. Modeling and control of three phase motors: vector control of synchronous motors, numeric control by DSP controllers. Paris: Ellipses, 2000

3. Ouhrouche M, Lefebre A, Do X D. Application of an extended Kalman filter to rotor speed and resistance estimation in induction motor vector control. In: 1998 IEEE Canadian Conference on Electrical and Computer Engineering. Waterloo, Canada, 1998, 297-300

4. Benchouia M T, Zouzou S E. A. Golea A, Ghamri A. Modeling and simulation of variable speed system with adaptive fuzzy controller application to PMSM. In: IEEE International Conference on Industrial Technology ICIT, Hammamet, Tunisia, 2004, 683-687

5. Capolino G A, Goléa A, Hénao H. Modeling and simulation of variable speed control with sliding mode. In: Proceedings of International Conference on electromechanical regulation, Metz, France, 1992

6. Grabowski P Z, Kazmierkowski M P, Bose B K, Blaabjerg F. A simple direct-torque neuro-fuzzy control of PWM-inverterfedinduction motor drive. IEEE Transactions on Industrial Electronics, 2000, 47(4): 863-870

7. Benchabnae F, Titaouine A. Sensorless control strategy for permanent magnet synchronous motor fed by AC/DC/AC converter, In: IEEE International Conference on Electrical Machines ICEM.
Rome, Italy, 2010, 1-6

8. Lin B R. High power factor $\mathrm{AC} / \mathrm{DC} / \mathrm{AC}$ converter with random PWM. IEEE Transactions on Aerospace and Electronic Systems, 1999, 35(3): 935-943

9. Jezernik K. VSS control of unity power factor. IEEE Transactions on Industrial Electronics, 1999, 46(2): 325-332

10. He Y Y, Jiang W. A new variable structure controller for direct torque controlled interior permanent magnet synchronous motor drive, In: Proceedings of the IEEE International Conference on Automation and Logistics. Jinan, China, 2007, 2349-2354

11. Benchabane F, Titaouine A, Bennis O. Systematic fuzzy sliding mode approach combined with extended Kalman filter for permanent magnet synchronous motor control. Mediterranean Journal of Measurement and Control, 2011, 7(1): 183-189

12. Zelechowski M, Kazmierkowski M P, Blaabjerg F. Controller design for direct torque controlled space vector modulated (DTCSVM) induction motor drives. In: Proceedings of the IEEE International Symposium on Industrial Electronics. Dubrovnik, Croatia, 2005, 951-956

13. Oscar B, Altour G J, Maseda F J. A robust field oriented control of induction motor with flux observer and speed adaptation. In: Proceedings of ETFA 2003 IEEE Conference. Lisbon, Portugal, 2003, 245-252

14. Montanari M, Peresada S M, Rossi C, Tilli A. Speed sensorless control of induction motors based on reduced-order adaptive observer. IEEE Transactions on Control Systems Technology, 2007, 15(6): 1049-1064

15. Yahia K, Zouzou S E, Benchabane F. Indirect vector control of induction motor with on line rotor resistance identification. Asian Journal of Information Technology, 2006, 5(12): 1410-1415 